\title{
Globo de plasma: uma montagem simples com amplo potencial para discussões em sala de aula ${ }^{+*}$
}

\author{
João Paulo Casaro Erthal \\ Departamento de Química e Física - UFES \\ Filipe Eduardo da Silva Pirovani \\ Estudante de Graduação - UFES \\ Ramón Giostri Campos \\ Departamento de Química e Física - UFES \\ Alegre - ES
}

\section{Resumo}

Devido à importância e necessidade da inserção da Física moderna e contemporânea no currículo de Física do ensino médio, este artigo apresenta e explicita a confecção e montagem de um globo de plasma alternativo, produzido com material de fácil aquisição, podendo esse ser reproduzido por professores e estudantes com facilidade. $O$ aparato tem o potencial de subsidiar discussões norteadas pelos temas estruturadores propostos em documentos oficiais brasileiros, de forma contextualizada, relacionando o fenômeno com a natureza e com aplicações tecnológicas presentes no cotidiano dos estudantes.

Palavras-chave: Globo de plasma. Ensino de Física contemporânea.

\footnotetext{
${ }^{+}$Plasma globe: a simple mounting with large potential for discussions in classroom

* Recebido: novembro de 2013.

Aceito: junho de 2014.
} 


\begin{abstract}
Given the importance and necessity of integration of Modern and Contemporary Physics in High School curriculum, this article shows how to make an alternative plasma globe with easily acquired materials, that can be easily reproduced by teachers and students. The apparatus has the potential to support discussions guided by structuring themes proposed in Brazilian official documents, in a contextualized way, which shows the relationship between the phenomenon, the natural world and technological applications present in the daily lives of students.
\end{abstract}

Keywords: Plasma globe. Contemporary Physics teaching.

\title{
I. Introdução
}

A discussão de temas de Física contemporânea e sua relação com as tecnologias que nos rodeiam vêm sendo bastante apresentadas, testadas e implementadas por pesquisadores e professores preocupados com a melhoria e adequação do ensino de ciências. Buscar uma formação de cidadãos capazes de discernir o verdadeiro papel da ciência e da tecnologia, seus valores e ideologias, se torna tão importante quanto a garantia ao acesso a elas. Uma sociedade alfabetizada científica e tecnologicamente é capaz de propiciar uma melhor perspectiva de desenvolvimento e qualidade de vida.

O entendimento acerca de assuntos científicos, compreendendo seus significados e aplicabilidade, é mais do que uma necessidade: é uma questão de sobrevivência para a atualidade. Ser alfabetizado cientificamente é saber ler a linguagem em que está escrita a natureza, ou seja, um analfabeto científico é incapaz de ler o universo (CHASSOT, 2003).

É necessário direcionar o ensino de ciências, para que o conhecimento adquirido vá além da sala de aula e para que o aluno faça a conexão entre ciência e tecnologia, utilizando-as como empreendimento social, além de meio para desenvolver suas habilidades e sua compreensão do mundo em que está inserido.

Um tema que pode ser ricamente explorado nessa perspectiva de alfabetização científica e tecnológica é a Física dos plasmas. Os plasmas podem ser encontrados em tecnologias atuais como, o tokamak, que é o engenho mais promissor, até o momento, para a obtenção da fusão termonuclear, motores propulsores de 
veículos espaciais, televisores, lâmpadas fluorescentes, letreiros de luz néon, entre outras. Além disso, estão presentes em fenômenos naturais como as auroras boreais e os relâmpagos.

O plasma consiste em uma combinação eletricamente condutora e interativa de um número significante de partículas carregadas e não carregadas, íons positivos, elétrons negativos, campos elétricos e magnéticos (REIS, 2012; SILVA et al., 2005).

O plasma também é chamado de "quarto estado da matéria", em extensão aos estados sólido, líquido e gasoso. Esta descrição foi usada primeiramente por William Crookes (1832-1919) em 1879. Em 1928, Irving Langmuir (1881-1957) realizou estudos das oscilações de natureza eletrostática em um gás ionizado dentro de um tubo de baixa pressão e determinou a propriedade elétrica de neutralidade deste gás, sendo capaz de responder a campos elétricos e magnéticos. Com isso, ele introduziu o conceito de "plasma" na Física para referenciar um gás ionizado (ROTH, 1995 apud ZUCOLOTTO JUNIOR, 2006).

Segundo Damásio e Calloni (2008), chamar o plasma de quarto estado da matéria não é justo, uma vez que esse deveria ser chamado de primeiro estado da matéria, pois os plasmas são o estado físico dominante da matéria visível no universo. Cerca de 99\% da matéria do universo está no estado de plasma (KEITANI; HOYAUX 1973, apud FELIPINI, 2005). Apesar disso, o tema praticamente não é discutido no ensino médio.

Nesse sentido, Tavares e Hora (2009), ao realizarem uma pesquisa bibliográfica em livros do ensino médio, constataram que nenhum dos livros analisados fazia menção aos plasmas.

Com a falta de conteúdos sobre plasmas nos livros didáticos para estudantes do ensino básico e com a defasagem existente entre os conteúdos do currículo atual e os conhecimentos científicos contemporâneos, raras são as discussões sobre o tema nas salas de aula do ensino médio. Pirovani e colaboradores (2013) em um trabalho sobre o levantamento de concepções sobre os plasmas verificaram que alunos do ensino médio praticamente desconhecem informações sobre o tema.

Trabalhar com o tema em turmas do ensino médio associando-o a tecnologias e fenômenos naturais nos quais está presente é uma ótima oportunidade de motivar os estudantes a se interessarem pela Física e pela ciência. Esse trabalho pode ser subsidiado pela utilização de um aparato experimental demonstrativo, como um globo de plasma. A exploração de um globo de plasma, em sala de aula, pode estar relacionada a diferentes temas estruturadores para o ensino de Física, sugeridos nos Parâmetros Curriculares Nacionais (BRASIL, 1999), tais como: 
- Movimentos - variações e conservações: podem-se associar os plasmas à fluidodinâmica, uma vez que os plasmas possuem todas as propriedades dinâmicas dos fluidos.

- Calor, ambiente, fontes e usos de energia: uma vez que é possível discutir como a matéria muda de um estado físico para outro à medida que se fornece energia térmica ao sistema.

- Equipamentos eletromagnéticos e telecomunicações: vários equipamentos eletrônicos modernos utilizam tecnologias provindas de estudos com plasmas. Além disso, os plasmas são formados de partículas que conduzem eletricidade. Eles tanto geram como sofrem a ação de campos eletromagnéticos.

- Universo, Terra e vida: sendo a maior parte do universo composta de plasma, pode-se discutir a existência do plasma no ambiente interplanetário, no campo magnético da Terra, no vento solar, nas estrelas, no interior do Sol, etc.

Além dessa variedade de temas que podem ser explorados, a discussão em sala de aula sobre a Física dos plasmas, e consequentemente da Física moderna e contemporânea, pode despertar a curiosidade dos estudantes no reconhecimento da Física como um empreendimento humano e com isso, estimular os jovens a seguirem carreiras científicas.

Ostermann e Moreira (2001, apud SILVA e ASSIS, 2012) defendem ser fundamental a produção de materiais didáticos associados aos temas de Física moderna e contemporânea que sejam acessíveis aos professores e aos alunos do ensino médio, de modo que esses possam subsidiar discussões sobre os temas e também o ensino de atitudes e de conceitos.

Dentro desse contexto, este trabalho descreve a construção de um globo de plasma alternativo, utilizando material de baixo custo e de fácil aquisição.

\section{Montagem do equipamento}

De forma simplificada, um globo de plasma é constituído de uma esfera de vidro preenchida internamente com um gás a baixa pressão, geralmente neônio ou argônio, além de um circuito de alta voltagem.

Para a confecção do globo de plasma alternativo é necessário:

$>$ Uma lâmpada incandescente (queimada ou não) de $100 \mathrm{~W}$.

$>$ Um suporte com bocal para lâmpada.

$>$ Fita isolante.

$>$ Um suporte de madeira.

$>$ Uma chave comutadora.

Fios de cobre encapados. 
Uma lâmpada fluorescente.

Um ignitron - acendedor automático de fogão, facilmente encontrado em lojas de consertos de fogão e ferros-velhos.

Para montagem do globo de plasma alternativo (Fig. 1), deve-se inicialmente construir o suporte de madeira que é constituído por um caixote retangular e por uma base inferior.

Para isso devem ser cortadas duas tábuas com $12 \mathrm{~cm}$ por $24 \mathrm{~cm}$, que servirão de tampos laterais do caixote; duas tábuas de $12 \mathrm{~cm}$ por $21 \mathrm{~cm}$, que servirão de tampos frontal e traseiro do caixote; uma tábua de $21 \mathrm{~cm}$ por $24 \mathrm{~cm}$ para tampo superior do caixote; e uma tábua de $30 \mathrm{~cm}$ por $50 \mathrm{~cm}$ para servir de base inferior para o aparato. A espessura das tábuas pode variar de acordo com o material que se tenha disponível, porém é aconselhável utilizar algo entre $0,5 \mathrm{~cm}$ e $2,0 \mathrm{~cm}$ para que o aparato não fique frágil ou robusto em demasia.

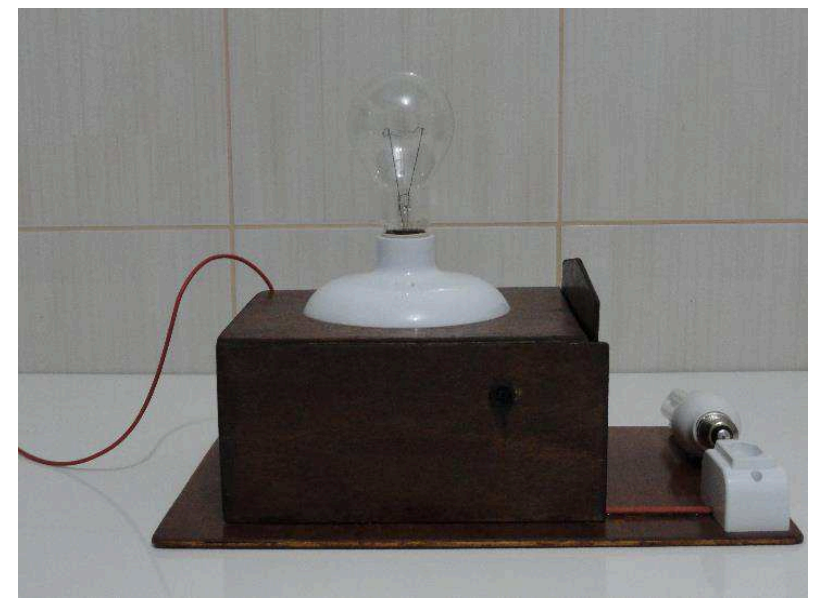

Fig. 1 - Globo de plasma alternativo.

No tampo superior do caixote devem ser feitos dois furos, sendo um no centro e outro próximo a algum dos vértices, para passagem de fiação elétrica. $\mathrm{Na}$ parte inferior dos dois tampos laterais deve-se fazer um sulco, no qual se encaixará o tampo traseiro, de modo que esse possa ser facilmente removido para demonstrações e reparos. O tampo traseiro também deve ter um pequeno rebaixo para passagem de fiação. 
Após a preparação das madeiras deve-se proceder a montagem do caixote sobre a base inferior, podendo ser pregado, parafusado ou colado. Na sequência deve-se fixar o suporte para lâmpada sobre o caixote.

No interior do caixote será fixado o ignitron. A chave comutadora e a tomada podem ser fixadas na base principal ou nas laterais do caixote. $\mathrm{Na}$ figura seguinte o tampo traseiro foi retirado, permitindo a visualização completa dos componentes do aparato (Fig. 2).

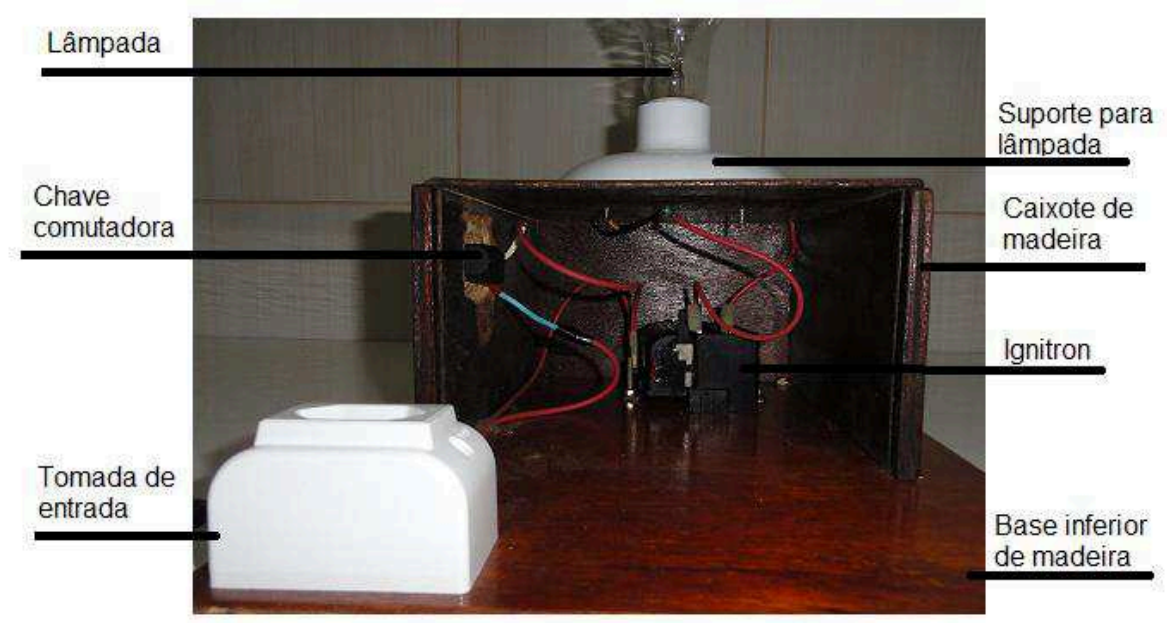

Fig. 2 - Globo de plasma alternativo sem o tampo traseiro.

O esquema da ligação elétrica envolvendo lâmpada, ignitron, chave comutadora e tomada de entrada pode ser visualizado na Fig. 3.

De acordo com a Fig. 3, um dos fios que saem do ignitron deve ser ligado à lâmpada e o outro deve ficar livre, de modo que possa ser utilizado como fio intensificador dos raios gerados no interior da lâmpada. Vale salientar que pode ser utilizado qualquer par de bornes, dentre os quatro pares que estão representados na figura.

De acordo com Bittencourt (2004) um plasma pode ser produzido através do aumento da temperatura de uma substância até que seja obtido um nível elevado de ionização. Em condições de equilíbrio termodinâmico, o grau de ionização e a temperatura dos elétrons estão estreitamente relacionados. Esta relação é dada pela equação de Saha, apresentada a seguir. 


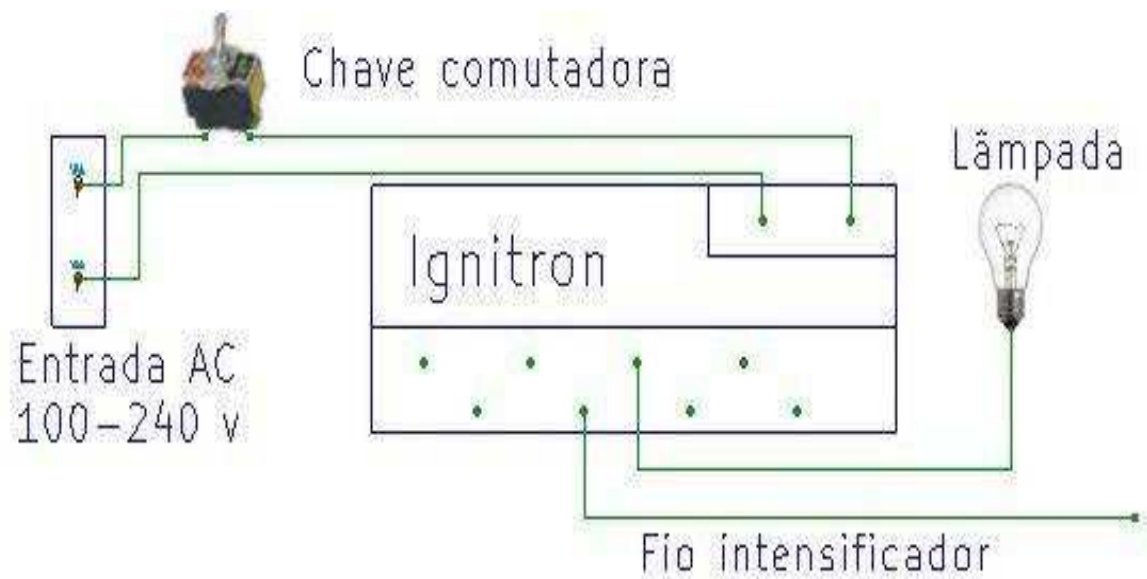

Fig. 3 - Circuito elétrico do globo de plasma alternativo.

$$
\frac{n_{i}}{n_{n}}=2,405 \times 10^{21} T^{\frac{3}{2}} \frac{1}{n_{i}} \exp \left(\frac{-U}{k T}\right)
$$

Essa equação tem origem na Física Estatística e descreve o processo de ionização parcial de um gás. A concentração iônica, $n_{i}$, corresponde à quantidade de átomos ionizados no gás. Já a concentração de átomos neutros, $n_{n}$, relaciona-se com a anterior de tal forma que o somatório dessas duas quantidades representa a concentração total de partículas no gás. A energia $U$ presente na exponencial, é a primeira energia de ionização, ou seja, a energia necessária para se retirar um elétron da camada de valência do gás em questão. A temperatura do gás é representada por $T$ e $k$ é a constante de Boltzmann, cujo valor é $1,38 \times 10^{-23} \mathrm{~J} / \mathrm{K}$.

No globo de plasma proposto, a diferença de potencial entre o vidro e o ignitron é muito alta, entre seis e oito mil volts, e com isso o gás inerte contido dentro da lâmpada sofre ionização, e consequente aumento de temperatura, havendo um deslocamento de cargas. Essas cargas excitam os elétrons do gás, que ao voltarem ao seu estado inicial emitem raios luminosos em várias direções. Quando o fio intensificador é encostado no vidro, ele faz o papel de aterramento, fazendo com que o raio fique mais brilhante naquela direção (Fig. 4).

Além da utilização do fio intensificador, os raios podem ser visualizados ao se aproximar a mão do globo, havendo faíscas entre o globo e as pontas dos dedos. Outra demonstração atraente ocorre com uma lâmpada fluorescente, que pode ser aproximada do globo e emitir luz (Fig. 5). Esses efeitos podem despertar a 
curiosidade dos estudantes em sala de aula e são interessantes atrações para as feiras de ciências.

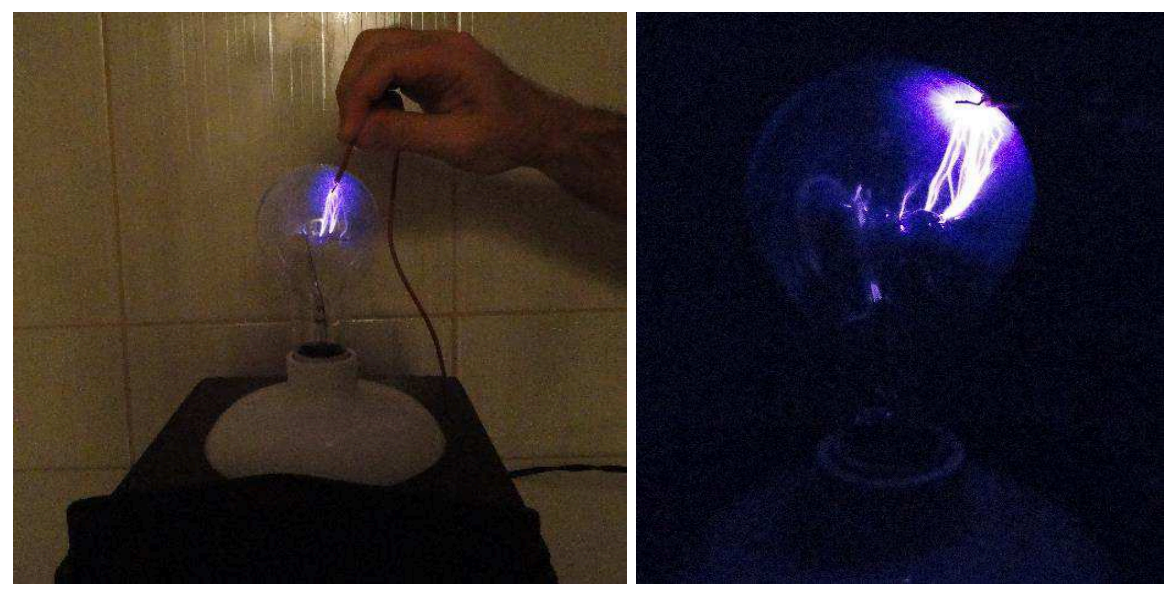

Fig. 4 - Globo de plasma alternativo em funcionamento utilizando fio intensificador.

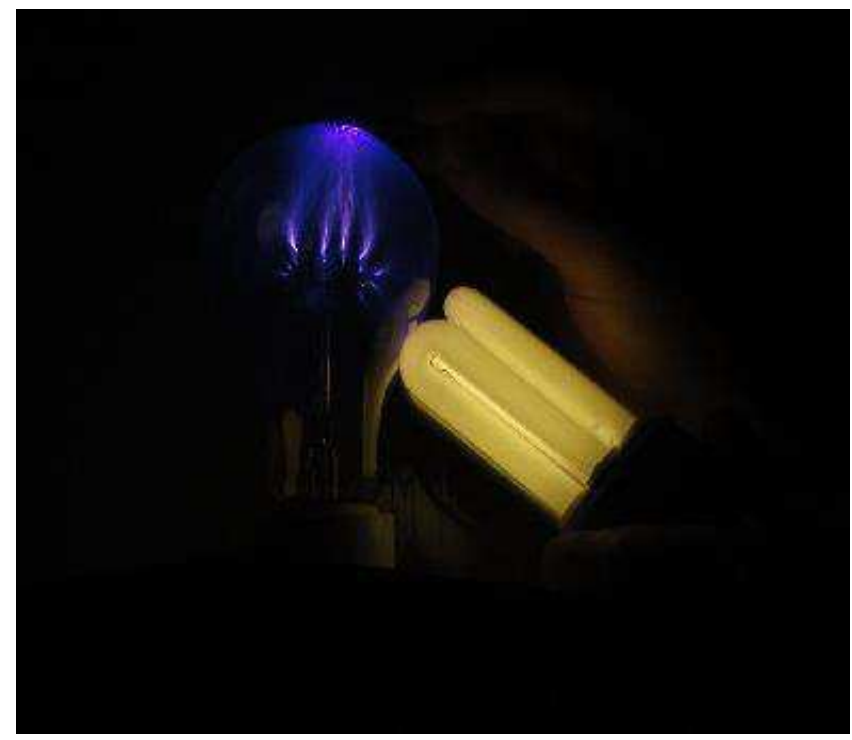

Fig. 5 - Lâmpada fluorescente e dedos aproximados do globo de plasma alternativo.

Erthal, J. P. C. et al. 
Uma das características básicas que distinguem o comportamento de plasmas em relação a fluídos e sólidos comuns é a existência de efeitos coletivos. Cada partícula carregada interage com uma série de outras partículas carregadas resultando em importantes efeitos coletivos que são responsáveis pela riqueza de fenômenos físicos associados aos plasmas (BITTENCOURT, 2004), como os efeitos visualizados no globo.

Salienta-se que alguns cuidados devem ser tomados durante a confecção e utilização do globo de plasma proposto. Devido alta tensão gerada, e consequente baixa corrente elétrica, da ordem de $1 \mathrm{~mA}$, não deve-se encostar a ponta do fio intensificador em partes do corpo humano, pois isso poderá gerar desconfortos térmicos ou pequeninos choques. Manutenções do aparato devem ser realizadas com este desligado da tomada, visto que essa possui correntes elétricas que podem causar choques danosos. Além disso, recomenda-se que durante a utilização do experimento, use-se calçados isolantes e não seja estabelecido contato com objetos metálicos como suporte de bancadas e armários, a fim de se evitar que as pequenas correntes geradas passem pelo corpo humano.

Esse aparato possui o potencial de atrair a atenção dos estudantes. Nessa perspectiva, uma excelente maneira de se explorar o tema em sala de aula, com utilização do globo de plasma alternativo, pode ser pautada na teoria sociocultural de Vygotsky, na qual interação social entre os participantes, mediada pela ação de um parceiro com mais conhecimento, pode subsidiar momentos de reflexão, motivação, cooperação e aprendizado.

A escolha por essa teoria justifica-se por ela oferecer um sistema de referência capaz de contribuir para a melhoria do ensino sem implicar condições ou recursos não existentes na grande maioria das escolas e universidades. Na perspectiva vygotskyana, o professor deve aproveitar os conhecimentos dos estudantes e uni-los às atividades que deseja desenvolver em sala de aula. Deve desafiar o aluno de modo que esse possa reproduzir uma operação mental que não seria produzida isoladamente. Dessa forma, o experimento deve contribuir para iluminar os processos e oferecer o máximo de oportunidades para o estudante se engajar nas atividades (ERTHAL, 2011).

\section{Conclusão}

O globo de plasma apresentado tem sido utilizado em salas de aula do ensino médio e em mostras e feiras de ciências, despertando bastante interesse e a curiosidade dos alunos. 
Diversos são os temas relacionados ao estudo de Física e de Química que podem ser evidenciados pelo professor com a utilização desse aparato. A interação dos estudantes com esse equipamento pode fomentar discussões sobre a natureza e sobre tecnologias atuais presentes no cotidiano desses alunos, contribuindo para redução do analfabetismo científico.

$\mathrm{O}$ crescimento da tecnologia dos plasmas pode gerar impactos nos processos de inovação no Brasil, sendo que os estudos da área possuem um caráter multidisciplinar, pois agregam pesquisadores de diversas áreas como Física, Química, Biologia, Engenharia, Medicina, entre muitas outras. A compreensão de temas básicos sobre plasmas é fundamental para uma formação focada na cidadania e no conhecimento global.

Dessa forma, o globo de plasma apresentado aparece como um material suplementar para a contemplação do tema em salas de aula. Devido a sua simplicidade, a montagem proposta pode ser realizada com facilidade por professores e estudantes interessados.

\section{Referências}

BITTENCOURT, J. A. Fundamentals of plasma physics. New York: Springer, 2004.

BRASIL. MINISTÉRIO DA EDUCAÇÃO. SECRETARIA DE EDUCAÇÃO MÉDIA E TECNOLÓGICA. Parâmetros Curriculares Nacionais: ensino médio. Brasília: MEC, 1999. Disponível em:

$<$ http://portal.mec.gov.br/index.php?id=12598:publicacoes\&option=com_content \&view=article>. Acesso em: 02 jun. 2013.

CHASSOT, A. Alfabetização científica: uma possibilidade para a inclusão social. Revista Brasileira de Educação, Rio de Janeiro, n. 22, 2003.

DAMASIO, F.; CALLONI, G. Plasma: dos antigos gregos à televisão que você quer ver. Física na Escola, v. 9, n. 1, 2008.

ERTHAL, J. P. C. Estabelecimento de relações entre a formação inicial de professores de Física e o ensino dessa disciplina para jovens e adultos: uma investigação pautada em atividades experimentais. 2011. 221f. Tese (Doutorado em Ensino de Ciências) - UENF, Campos dos Goytacazes. 
KEITANI, M. A.; HOYAUX, M. F. Plasma Engineering. Londres: London Butterworths, 1973, apud FELIPINI, C. L. Noções sobre plasma térmico e suas aplicações. Revista Integração, ano XI, n. 41, p. 147-151, 2005.

OSTERMANN, F.; MOREIRA, M. A. Atualização do currículo de Física na escola de nível médio: um estudo dessa problemática na perspectiva de uma experiência em sala de aula e da formação inicial de professores. Caderno Catarinense de Ensino Física, Florianópolis, v. 18, n. 2, p. 135-151, ago. 2001 apud SILVA, L. F.; ASSIS, A. Física moderna no ensino médio: um experimento para abordar o efeito fotoelétrico. Caderno Brasileiro de Ensino de Física, Florianópolis, v. 29, n. 2, p. 313-324, ago. 2012.

PIROVANI, F. E. S.; ERTHAL, J. P. C.; CAMPOS, R. G. Investigação sobre a compreensão de estudantes do ensino médio sobre o quarto estado da matéria. In: ENCONTRO NACIONAL DE PESQUISA EM EDUCAÇÃO EM CIÊNCIAS, IX, 2013, Águas de Lindóia. Atas...

REIS, N. T. O. Plasmas - O estado físico do Universo visível. Disponível em: $<$ http://educacaoespacial.files.wordpress.com/2010/10/plasmas.pdf $>$. Acesso em: 12 jul. 2013.

ROTH, J. R. Industrial plasma engineering. v.1. Philadelphia: Institute of physics publishing, 1995, apud ZUCOLOTTO JUNIOR, C. G. Geração de hidrogênio e negro de fumo pela pirólise do gás natural utilizando uma tocha de plasma. 2006, 86f. Dissertação (Mestrado em Física) UFES, Vitória.

SILVA, I. P. et al. A abordagem das bolhas de plasma no ensino médio e a aplicação de conceitos de Física básica. In: SIMPÓSIO NACIONAL DE ENSINO DE FÍSICA, XVI, 2005, Rio de Janeiro. Disponível em:

$<$ http://www.sbf1.sbfisica.org.br/eventos/snef/xvi/cd/resumos\%5CT0031-1.pdf>. Acesso em: 22 out. 12.

TAVARES, M. R. S.; HORA, P. H. A. Proposta e avaliação de alunos e professores sobre a inclusão do estudo do plasma no ensino médio. In: SIMPÓSIO BRASILEIRO DE EDUCAÇÃO QUÍMICA, VII, 2009, Salvador. Disponível em: <http://www.abq.org.br/simpequi/2009/trabalhos/107-5991.htm>. Acesso em: 27 ago. 2012. 